\title{
BOVINE WELLFARE HANDLED IN ADAPTED CORRAL WITH UNCONVENTIONAL MATERIALS
}

\author{
Diogo de L. Sartori ${ }^{1 *}$, Erika Y. Nakanishi ${ }^{2}$, Julio C. M. Cravo ${ }^{2}$, Luciane S. Martello², \\ Juliano Fiorelli ${ }^{2}$
}

${ }^{1 *}$ Corresponding author. São Paulo State University (UNESP)/ Tupã - SP, Brazil.

E-mail: diogo.sartori@unesp.br | ORCID ID: https://orcid.org/0000-0002-4957-1408

\section{KEYWORDS \\ particle sheet, rural buildings, animal reactivity, body surface temperature.}

\begin{abstract}
This study aimed at evaluating bovine behavioral parameters managed in crowding pens built with modular panel of reforestation wood and homogeneous particle sheets of sugarcane bagasse and in conventional wooden crowding pens. The animals treated had their body surface temperature measured by the infrared thermography method and the behavior evaluated through the flight time parameters and the behavior score in the crowding pens. The results indicated that the animals managed in these buildings showed no difference in the behavioral parameters, but the mean and maximum superficial body temperatures were lower in the animals managed in the crowding pens of modular panel.
\end{abstract}

\section{INTRODUCTION}

The management activities in bovine production systems, whether to pasture or confined, require adequate facilities for the handling of animals, called corral handling. Traditionally in Brazil, bovine handling facilities are built using the rectilinear model and "hardwood", and more recently with the use of timber such as treated eucalyptus or precast concrete posts that use steel cord to close the fences. (Euclides Filho et al., 2002).

The corral handling, comprises a group of structures necessary for the handling of the animals and are constituted by holding pens, crowding pen, working chute, scale and loading chute. It is used to safely and efficiently confine bovines to perform several procedures such as observation, routine sanitary handling, weighing, sorting and other management procedures that are indispensable and are part of the bovine production system (Bicudo et al., 2002).

Euclides Filho et al. (2002) state that facilities improperly constructed, in addition to endangering animals and people involved in the handling, make the handling time longer by increasing the reactivity of the animals, making them more stressed, which can lead to problems and losses to the production system, such as carcasses and leathers of lower quality when the animals are intended for slaughter.

Details such as the type of fence used in the corral, especially in areas with greater agglomeration of animals, is related to the handling time and stress of the animals. Fences made of intercalate boards with open spaces allow the bovine to become distracted or frightened by external events, causing the animals to stop, retreat and even jump, delaying the finalization of the work and may even cause accidents. When sealing these spaces, in the crowding pens and in the squeeze chute where the animals clump together and are closer to their managers, this effect is minimized (Paranhos da Costa et al., 2002).

Thus, a facility intended for bovine handling, when well designed and constructed in conjunction with an adequate management, reduces bruises and hematomas in the animals' carcasses, decreases the stress suffered by the animal, provides a beneficial behavioral response to the animal (provides animals with a calmer temperament), reduces animal reactivity, reduces handling time, and also reduces work-related accidents such as injury to workers (Grandin 1983, Fox et al., 2015, Simon et al., 2016).

A behavioral aspect of interest in bovines is the temperament, which can be understood as the reaction of animals related to stimuli caused by human activities in the different production systems, causing a beneficial or harmful behavioral response to animals. Animals with more aggressive temperament have a negative impact on productivity and animal production, since they present lower weight gain and worse carcass quality, among others impacts (Maffei, 2009). The temperament can be quantified by means of a behavior score on a scale from 1 to 5, through a visual analysis (Arthington et al., 2008; Sebastian et al., 2011; Piovezan et al., 2013; Francisco et al. 2015), and also by means of the evaluation of the escape or flight time (Vetters et al., 2013, Piovezan et al.,

\footnotetext{
${ }^{2}$ University of São Paulo (USP)/ Pirassununga - SP, Brazil.

Received in: 3-21-2017

Accepted in: 3-6-2019
} 
2013, Francisco et al., 2015). The escape or flight time is directly related to the animal's weight gain, according to Burrow \& Dillon (1997) animals that leave the contention squeeze chute quietly perform better for weight gain.

The evaluations of behavior score and escape time are considered as adequate tools like temperament indicators for bovine, and can also be used in the selection of bovine with better temperament (Piovezan et al., 2013).

New technologies are being used to advance animal research through non-destructive and less invasive methods to animals, decreasing more and more stress situations. An example is the thermal imaging analysis using infrared thermography (Schaefer et al., 2004; Church et al., 2014; Martello et al., 2016; Xiong et al., 2017). This technique is based on the theory that all bodies emit thermal energy in the infrared range of the electromagnetic spectrum, whereas the infrared thermography analysis transforms this thermal energy into a visible image (Meola \& Carlomagno, 2004). This technique has been widely used to measure physiological or pathological alterations in the superficial temperature of animals for the early detection of infections and inflammatory processes (Schaefer et al., 2004; Alsaaod et al., 2014), to monitor natural or animal behavior or in certain handling conditions (Stewart et al., 2007; Herborn et al., 2015) and for evaluating the thermal comfort in animal production facilities (Fiorelli et al, 2012.).

On the scope presented, this study aimed to evaluate the bovine temperament handled in corral with two building systems: 1) crowding pens built with modular panel of reforestation wood and homogeneous particle sheets of sugarcane bagasse and 2) conventional wooden crowding pens, through behavioral analysis and infrared thermography analysis.

\section{MATERIAL AND METHODS}

\section{Corral handling}

A corral handling, of rectilinear model, was used in the evaluation, located at the Campus of the Faculty of Animal Science and Food Engineering (FZEA/USP) in the city of Pirassununga-SP. The facility area of the animal evaluation was the crowding pens structure, where two types of conformation were tested, as shown in Figure 1. The first conformation had a wood structure with intercalate boards with spaces, with an area of $8.7 \mathrm{~m}^{2}$, conventionally found in Brazil (Figure 1a). The second one had its sides coated, being used for closing the modular panels with particles sheet of sugarcane bagasse (Fiorelli et al., 2013; Sartori et al., 2015), presenting an area of $6.5 \mathrm{~m}^{2}$ (Figure 1b).

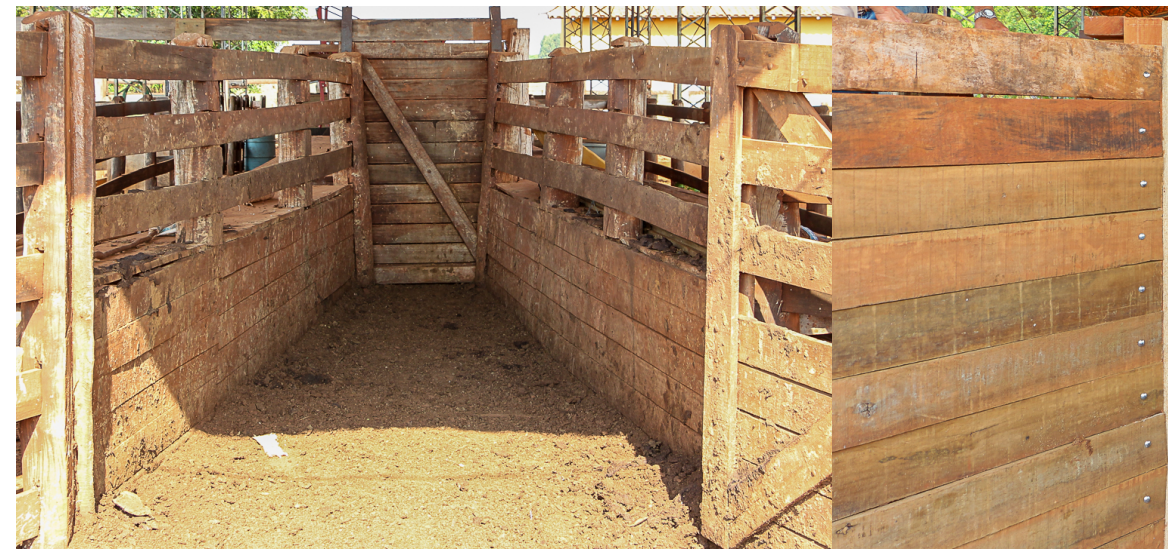

(a)

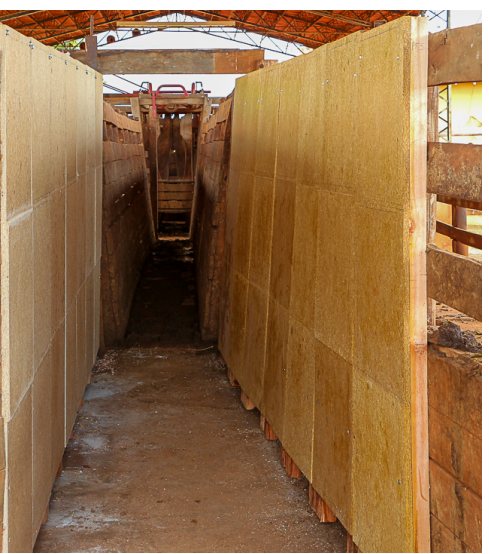

(b)

FIGURE 1. Crowding pens structure of the corral: (a) Conventional. (B) With Modular Panels.

\section{Animals}

Nellore adult cows with a mean age of 9 years and mean weight of $642 \mathrm{~kg}$ were used to perform the handling and measurement of the evaluated parameters, members of the matrices herds from the FZEA / USP. The use of these animals in the experiment followed the current legislation, Federal Law 11794, of October 08, 2008 and State Law 11977, of August 25, 2008, according to the opinion issued by the local board of the Ethics Committee in Research of FZEA / USP.
The characteristics of the animals are described in Table 1, and the amount of animals used in the experiment was determined according to the capacity of each crowding pens model, being $1.5 \mathrm{~m}^{2}$ per animal, so for the conventional crowding pens six animals, whereas for the crowding pens with the modular panels four animals were used. In order to carry out the animal evaluation, only four animals were selected, and the two additional animals from the conventional system were only used to maintain the stocking rate for the two crowding pens models during the handling.

TABLE 1. Information of the animals used in the experiment.

\begin{tabular}{ccc}
\hline Identification (numbering) & Age (years) & Weight (kg) \\
\hline 295 & 13 & 628 \\
1978 & 8 & 647 \\
2137 & 8 & 683 \\
3301 & 7 & 609 \\
\hline Average & 9 & 642 \\
\hline
\end{tabular}




\section{Management and Behavior Parameters}

The evaluation of the bovine behavior was made through temperament measures (behavior score and flight time) and body surface temperature. The evaluation was performed on animals handled in the corral with the crowding pens with the modular panels and also, in the corral with the crowding pens in its conventional structure, as described previously. These measurements were performed at two times and repeated three times for each of the two crowding pens conformations. Animal behavioral evaluations were initiated shortly after the group was conducted and contained within the crowding pens for the two different models of facility.

\section{Behavior score}

The behavior score analysis was performed based on the adapted methodology described by Arthington et al. (2008) and Sebastian et al. (2011). A temperament scale assigned to each animal was used during the handling in the crowding pen, with the evaluation always performed by the same observer. The behavior score was recorded by means of direct observation, focal sampling with continuous collection route for a period of 20 seconds for each animal, being assigned a score based on a scale from 1 to 5 points $(1=$ calm, without movement; $2=$ slightly uneasy, slight displacement, slightly alarmed; $3=$ moderately alarmed, writhing, occasional tail shake displacement; 4 = very alarmed, continuous vigorous movement, tail agitation, head up; $5=$ very excited and aggressive, twisted body, fight violently).

For the analysis of the bovine behavioral score managed in the conventional crowding pens and with modular panels, the Likelihood Ratio test was used to compare the means of the scores (scale from 1 to 5) attributed to each group.

\section{Flight time}

The flight time parameter was determined as the time the animal took to travel a distance of $2 \mathrm{~m}$ immediately after being individually released from the crowding pens (Vetters et al., 2013; Piovezan et al., 2013). The marking occurred in the squeeze chute, because it is the structure of the corral that is in continuity of the handling flow of the corral after the crowding pens, and the times were registered manually by an observer using a digital chronometer.

For the analysis of the crowding pens flight time, it was used randomized block design (RBD) with the days of handling considered blocks and composed by the Closing factor, constituted by the levels Modular Panel and Conventional, totaling 2 treatments. Because of the fact that only one contrast was present, the F test (ANOVA) at $\mathrm{p}<0.05$ was used to investigate the effect of the treatments means.

\section{Surface body temperature}

The body surface temperature was measured using the infrared thermography method, using a Testo brand thermal imager, model $875-2 \mathrm{i}$ with thermal sensitivity $<50$ $\mathrm{mK}$ with integrated digital camera. The capture of the thermographic images was performed with each free animal, in a small pen of the corral in two moments for each handling performed, being the first one before the entrance of the animals in the crowding pens and the second after passing the animals through the crowding pens. Images were taken from both sides of the animals, and the imager was adjusted to the emissivity coefficient of 0.98 , a value used according to the manufacturer's recommendation for biological tissues.

For the image processing and evaluation, the software testo IRSoft 3.4 was used, where the thermograms analysis and the construction of the temperature histograms were performed. The thermogram analysis was done by selecting a more representative region of the animal side, by selecting an area in the elliptical format. This form of analysis was chosen because it allows a greater comprehensiveness and representativeness of the region of the animal body exposed to impacts with the lateral walls of the crowding pens, that could occur during the handling. With this analysis it was possible to obtain the maximum, minimum and average temperature of each animal and comparisons among the handlings performed for each type of the crowding pens closure.

The average superficial body temperature of the animals was analyzed in a $2 \times 2$ factorial scheme, according to a randomized block design (RBD) in which the factors studied were Closing and Moment. The Closing factor consisted of the Modular Panel and Conventional levels, while the Moment factor was composed of the Before and After levels, totaling 4 treatments. To investigate the effect of the treatments averages, the Tukey test was adopted at $\mathrm{p}<0.05$.

The maximum surface body temperature of the animals was analyzed according to a randomized block design (RBD), which was composed by the Closing factor, constituted by the Modular Panel and Conventional levels, totaling 2 treatments. The days of handling were considered blocks. Because the experiment presented only one contrast, the F test (ANOVA) at $\mathrm{p}<0.05$ was used to investigate the effect of the treatments mean.

\section{RESULTS AND DISCUSSION}

The average and maximum superficial body temperature, behavioral score and the bovines flight time of the crowding pen under handling were evaluated for the bovines' behavior parameters handled in crowding pen with modular panels and conventional, as previously described. Table 2 presents a summary of the results obtained, with all variables analyzed in the study, containing their respective numbers of observations $(\mathrm{N})$, mean, standard deviation (SD), coefficient of variation $(\mathrm{CV})$, minimum (MIN) and maximum (MAX) values for the parameters related to the bovine behavior evaluation. 
TABLE 2. Variables analyzed and their respective numbers of observations (N), mean, standard deviation (SD), coefficient of variation $(\mathrm{CV})$, minimum values (MIN) and maximum values (MAX) for bovine behavior parameters.

\begin{tabular}{ccccccc}
\hline VARIABLE & N & MEAN & SD & CV & MIN & MÁX \\
\hline T. Mean $\left({ }^{\circ} \mathrm{C}\right)$ & 48 & 32.3 & 1.53 & 5 & 27.5 & 34.8 \\
T. Max. $\left({ }^{\circ} \mathrm{C}\right)$ & 24 & 34.4 & 0.98 & 3 & 32.5 & 35.8 \\
BS & 24 & 2 & 0.72 & 45 & 1 & 3 \\
FT (s) & 24 & 24 & 58.39 & 41 & 37 & 250 \\
\hline
\end{tabular}

T. Mean = Mean surface body temperature; T. Max. = Maximum surface body temperature; $\mathrm{BS}=$ Crowding pens behavior score; FT $=$ Crowding pens flight time.

\section{Behavior score and flight time}

The animals' temperament handled in the crowding pen with modular panels and conventional was evaluated by means of the behavior score and the flight time. The aim was to obtain parameters for the animals' behavior when submitted to the same handling, trying to evaluate, through the comparison of the results, if the crowding pen with the presence of the modular panels influenced the animals' behavior. Table 3 shows the mean values of the behavior score and the flight time of each animal in the crowding pen with the modular panels and conventional.

TABLE 3. Mean values for behavior score and flight time for each animal in the crowding pens with modular panels and conventional.

\begin{tabular}{ccccc}
\hline \multirow{2}{*}{ Animal } & \multicolumn{2}{c}{ Behavior score (1-5) } & \multicolumn{2}{c}{ Flight time (1/100s) } \\
\cline { 2 - 5 } & Modular Panels & Conventional & Modular Panels & Conventional \\
\hline 295 & $2 \pm 1$ & $2 \pm 1$ & $77 \pm 35$ & $128 \pm 40$ \\
1978 & $2 \pm 1$ & $1 \pm 1$ & $180 \pm 28$ & $197 \pm 48$ \\
2137 & $2 \pm 1$ & $1 \pm 1$ & $153 \pm 101$ & $178 \pm 21$ \\
3301 & $1 \pm 1$ & $1 \pm 1$ & $86 \pm 47$ & $127 \pm 10$ \\
\hline Average & $2 \pm 1$ & $2 \pm 1$ & $124 \pm 68$ & $158 \pm 43$ \\
\hline
\end{tabular}

The statistical analysis for the behavior score and the flight time in the crowding pen was performed to identify whether there was a significant difference in the reactivity of the group of animals when handled in the crowding pen with modular panels and conventional. The results of this analysis are presented in Table 4.

TABLE 4. Behavior score and flight time of the animals for the crowding pens with modular panels (MP) and conventional (C).

\begin{tabular}{ccc}
\hline Type & $\begin{array}{c}\text { Behavior score } \\
(1-5)\end{array}$ & $\begin{array}{c}\text { flight time } \\
(1 / 100 \mathrm{~s})\end{array}$ \\
\hline Modular Panels & $2 \mathrm{~A}$ & $124 \mathrm{~A}$ \\
Conventional & $2 \mathrm{~A}$ & $158 \mathrm{~A}$ \\
\hline
\end{tabular}

Means followed by different capital letters in the column for behavior score differ by the likelihood test.

Means followed by different capital letters in the column for flight time differ by the $F$ test $(\mathrm{p}<0.05)$.

For both behavioral parameters, there was no significant difference between the group of animals when handled in the crowding pen with the modular panels and in the conventional. For the behavior score, it was assigned a score 2 to both handlings, demonstrating that animals remained mildly anxious with a slight displacement when in the presence of the person responsible for handling.
According to Francisco (2014), the behavior presented by the animals, represented by the score of the attributed behavior score, can be considered adequate for the handling to which they were submitted.

As for the flight times (124 and 158 hundredths of seconds) obtained for the group of animals handled in the crowding pen with modular panels and conventional, Burrow (1991, apud Barbosa Silveira et al., 2008) states that for this value range the behavior of these animals is classified as meek after the passage through the crowding pen.

The results presented for evaluating the behavior of the animals measured under both conditions demonstrates that the use of modular panels in the crowding pen did not cause changes in the behavior of the animals during handling. These results were considered as a positive indication that the crowding pen alteration, with the implementation of modular panels, did not alter and caused damage to the bovine management in this facility and also did not reduce the comfort of these animals.

\section{Body surface temperature}

The mean and maximum bodies surface temperatures of the animals handled in the crowding pen with modular panels and conventional, determined by means of infrared thermography, are shown in Table 5 and Table 6 . 
TABLE 5. Average temperature of the body surface of the animals before and after handling in the crowding pens with modular panels and conventional.

\begin{tabular}{ccccc}
\hline \multirow{2}{*}{ Animal } & \multicolumn{2}{c}{ Modular Panels } & \multicolumn{2}{c}{ Conventional } \\
\cline { 2 - 5 } & Before & After & Before & After \\
\hline 295 & $31.6 \pm 1.4$ & $31.9 \pm 1.4$ & $32.7 \pm 1.1$ & $33.7 \pm 0.3$ \\
1978 & $31.7 \pm 1.9$ & $32.8 \pm 1.0$ & $33.2 \pm 1.6$ & $33.4 \pm 1.0$ \\
2137 & $30.3 \pm 2.5$ & $31.2 \pm 2.1$ & $33.1 \pm 1.1$ & $33.3 \pm 0.8$ \\
3301 & $31.3 \pm 1.8$ & $31.7 \pm 1.5$ & $32.0 \pm 1.5$ & $32.9 \pm 0.4$ \\
\hline Average & $31.2 \pm 1.8$ & $31.9 \pm 1.4$ & $32.8 \pm 1.2$ & $33.3 \pm 0.7$ \\
\hline
\end{tabular}

TABLE 6. Maximum temperature of the body surface of the animals after the passage in the crowding pens with modular panels and conventional.

\begin{tabular}{ccc}
\hline Animal & Modular Panels & Conventional \\
\hline 295 & $33.5 \pm 1.3$ & $35.1 \pm 0.3$ \\
1978 & $34.4 \pm 0.9$ & $34.8 \pm 0.8$ \\
2137 & $33.4 \pm 1.3$ & $35.0 \pm 0.6$ \\
3301 & $34.3 \pm 1.0$ & $35.0 \pm 0.2$ \\
\hline Average & $33.9 \pm 1.1$ & $35.0 \pm 0.5$ \\
\hline
\end{tabular}

The values of the mean body surface temperature of the animals evaluated for the two types of crowding pens and measurement moments (before and after the handling), demonstrate that the body temperature remained within the standard considered suitable for Nellore breed, similar to values found by Santos et al. (2005), who obtained a mean value for skin temperature of Nellore cows, reared on pastures during the rainy and dry seasons, of $32.9^{\circ} \mathrm{C}$.

For the mean body surface temperature of the animals, no interaction $(p<0.05)$ was observed between the factors; crowding pen closure and the measurement moment of the body surface temperature of the group of animals (Table 7).
The analysis of the average body surface temperature of the animals, regarding the type of lateral closure of the crowding pen, showed that the group of animals handled in the crowding pen with modular panels had a significantly lower temperature, compared to those measured in animals handled in a conventional crowding pen $(p<0.05)$. As to the moment of body surface temperature measurement, it was verified that the group of animals had significantly lower mean body surface temperature before the handling $(\mathrm{p}<0.05)$.

For the maximum body surface temperature of the animals after the handling, there was a significant difference $(\mathrm{p}<0.05)$ for this parameter between the group of animals handled in a crowding pen with modular panels and in a conventional crowding pen (Table 8).

TABLE 7. Average temperature of the body surface of animals before and after the passage through the crowding pens with modular panels and conventional.

\begin{tabular}{lccc}
\hline \multirow{2}{*}{ Type } & \multicolumn{2}{c}{ Average temperature $\left({ }^{\circ} \mathrm{C}\right)$} & \multirow{2}{*}{ Average } \\
\cline { 2 - 3 } & Before & After & 31.5 B \\
\hline Modular Panels & 31.2 & 31.9 & $\mathbf{3 3 . 3 ~ A}$ \\
Conventional & 32.8 & 33.3 & \\
\hline Average & $\mathbf{3 2 . 0} \mathbf{~ b}$ & $\mathbf{3 2 . 6} \mathbf{~ a}$ & \\
\hline
\end{tabular}

Averages followed by different capital letters in the column and different lowercase letters in the row differ statistically by the $\mathrm{F}$ test ( $\mathrm{p}<0.05$ ).

TABLE 8. Maximum body surface temperature of animals after the passage through the crowding pens with modular panels and conventional.

\begin{tabular}{cc}
\hline Type & $\begin{array}{c}\text { Maximum temperature }\left({ }^{\circ} \mathrm{C}\right) \\
\text { Overall average }\end{array}$ \\
\hline Modular Panels & $\mathbf{3 3 . 9} \mathbf{~ B}$ \\
Conventional & $\mathbf{3 5 . 0} \mathbf{A}$ \\
\hline
\end{tabular}

Means followed by different capital letters in the column differ statistically by the $\mathrm{F}$ test $(\mathrm{p}<0.05)$.

The statistical analysis of the maximum body surface temperature of the animals showed that the group of animals handled in the crowding pen with the modular panels presented values significantly lower than the temperatures measured in the handling performed in the conventional crowding pen. In Figure 2 and 3 the examples of the thermogram before and after the handling of one of the animals evaluated, for the crowding pen with modular panels and for the conventional one, it is possible to observe the difference in the alteration of the body temperature of the animal after the handling for both models of crowding pen, and Figure 3 shows a more pronounced increase in body temperature after the passage through the conventional crowding pen. 


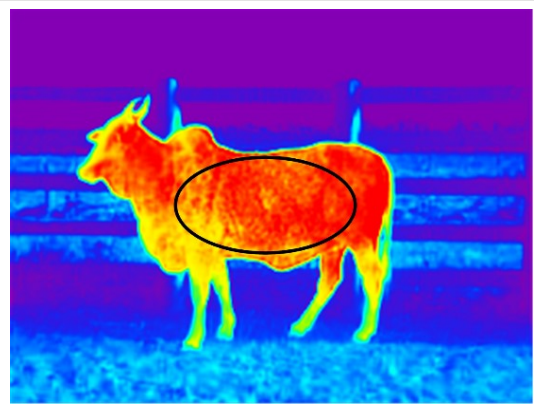

(a)

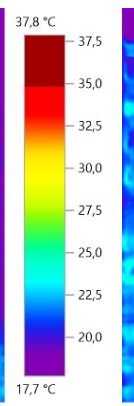

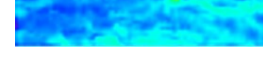

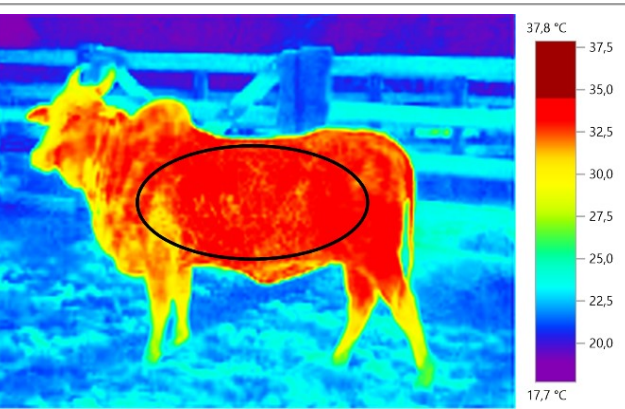

(b)

FIGURE 2. Thermogram of the animal 2137 before (a) and after (b) of the handling in the crowding pen with the modular panels.

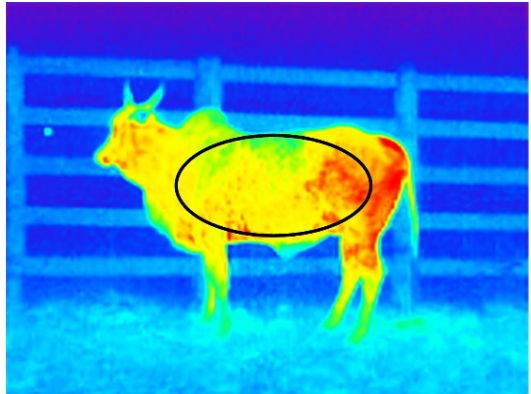

(a)
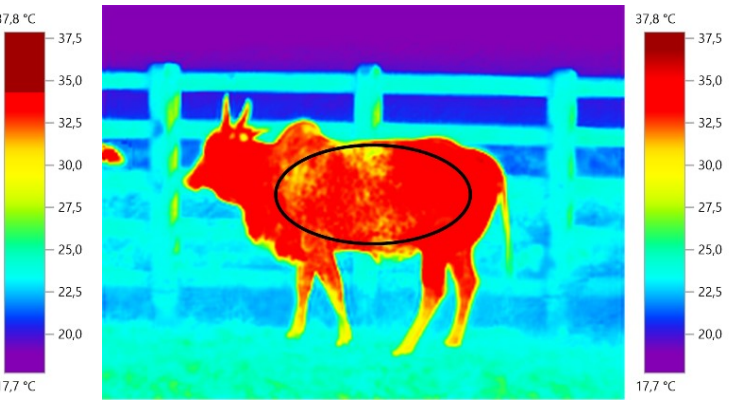

(b)

FIGURE 3. Thermogram of the animal 2137 before (a) and after (b) of handling in the conventional crowding pen.

Based on the results presented by the analysis of mean and maximum body surface temperature of the animals, it was evidenced that the use of modular panels and homogeneous particles sheets of sugarcane bagasse as lateral closure of the crowding pen, provided lower body temperatures to the animals handled when compared to crowding pen in its conventional format.

That is, with the increase in body surface temperature, it can be concluded that there is a negative interaction of the animal with the conventional crowding pen, consisting of intercalated wooden boards with spaces between them. Although there was no significant difference between the behavioral parameters of the animals handled in the two types of crowding pen, the difference in the body surface temperature of the animals may have occurred for two reasons, which may lead to a higher temperature increase. The first reason can be explained by the fact that the animals were more reluctant to enter the crowding pen and the second reason was because the animals remained more grouped, which are related to the lateral closure of the conventional crowding pen with spaces between the boards in an attempt to be kept apart from the sides as mentioned by Paranhos da Costa et al. (2002). Therefore, these facts can cause in the increase of the animals' body temperature, as evidenced, due to the greater generation of heat when handled in the conventional crowding pen.

This fact may be an indication that the use of modular panels collaborated with the decrease of the stress caused to the animals when submitted to the handling in this installation, probably due to the suitability in the crowding pen installation with the total closure of the open spaces between the boards of the lateral walls of the conventional model, preventing the animal from seeing the external movement. Another corroborating factor for this explanation may be the use of homogeneous particle sheets instead of the conventional crowding pen wood, because they have a lower hardness than the wood, which would cause less impact to the body of the animal when crashing to the side walls of the installation during handling.

Therefore, the use of the image analysis by means of thermographic analysis of the body surface has shown to be an adequate tool to measure the animal physiological response in relation to the type of installation to which it was submitted. Thus, it can be used to evaluate animal welfare, complementing the visual analysis, such as the behavior score and the flight time.

\section{CONCLUSIONS}

Regarding the bovines' behavioral parameters, when it was handled in the crowding pens with lateral closure using the modular panels and in the conventional crowding pens with wooden boards closure no significant difference was observed among the behavior presented by the bovines, indicating that the alteration of the building system did not influence the behavior of the animals.

For the body surface temperature, the animals handled in the crowding pens with modular panels presented, after the management, mean and maximum temperatures lower than those measured in the animals when managed in the conventional crowding pens, being an indication that this lateral closure system of the installation entails a lower stress to the animals when managed.

In this way, the modular panel presents itself as an efficient alternative solution for application in rural buildings, contributing not only to the improvement of the bovine management environment and the welfare of the animals, but also to the production system as a whole for adding a new proposal of material with the appeal of sustainability, for transforming an agro-industry byproduct into a new material. 


\section{ACKNOWLEDGMENTS}

The authors would like to thank FAPESP for supporting the research (proc. 2012 / 13881-2, proc 2013 / 19895-8, 2012 / 51467-3)

\section{REFERENCES}

Alsaaod M, Syring C, Dietrich J, Doherr MG, Gujan T, Steiner A (2014) A field trial of infrared thermography as a non-invasive diagnostic tool for early detection of digital dermatitis in dairy cows. The Veterinary Journal 199(2):281-285.

Arthington JD, Qiu X, Cooke RF, Vendramini JMB, Araujo DB, Chase Jr CC, Coleman SW (2008) Effects of preshipping management on measures of stress and performance of beef steers during feedlot receiving. Journal of Animal Science 86:2016-2023.

Barbosa Silveira ID, Fischer V, Farinatti LHE, Restle J, Alves Filho DC (2008) Relação entre genótipos e temperamento de novilhos Charolês $\times$ Nelore em confinamento. Revista Brasileira de Zootecnia 37(10):1808-1814.

Bicudo JR, Mcneill S, Turner LW, Burris R, Anderson J (2002) Cattle handling facilities: planning, components and layouts. Lexington, University of Kentucky Cooperative Extension Service AEN-82.

Burrow HM, Dillon RD (1997) Relationship between temperament and growth in a feedlot and commercial carcass traits of Bos indicus crossbreeds. Australian Journal Experimental Agriculture 37:407-411.

Church JS, Hegadoren PR, Paetkau MJ, Miller CC, RegevShoshani G, Schaefer AL, Schwartzkopf-Genswein KS (2014) Influence of environmental factors on infrared eye temperature measurements in cattle. Research in Veterinary Science 96(1):220-226.

Euclides Filho K, Euclides VPB, Corrêa ES (2002) Boas práticas na produção de bovinos de corte. Campo Grande, Embrapa Gado de Corte. 25 p. (Documentos, 129).

Fiorelli J, Sartori DL, Cravo JCM, Savastano Junior H, Rossignolo JA, Nascimento MF, Lahr FAR (2013) Sugarcane bagasse and castor oil polyurethane adhesivebased particulate composite. Materials Research 16(2):439-446.

Fiorelli J, Schmidt R, Kawabata CY, Oliveira CEL, Savastano Junior H, Rossignolo JA (2012) Eficiência térmica de telhas onduladas de fibrocimento aplicadas em abrigos individuais para bezerros expostos ao sol e à sombra. Ciência Rural 42(1):64-67.

Fox S, Ricketts M, Minton JE (2015) Worker Injuries Involving the Interaction of Cattle, Cattle Handlers, and Farm Structures or Equipment. Journal of agricultural safety and health 21(1):3-12.

Francisco CL (2014) Efeito do temperamento e do estresse nas características da carne de bovinos terminados em confinamento. Tese Doutorado, Botucatu, Universidade Estadual Paulista.
Francisco CL, Resende FD, Benatti JMB, Castilhos AM, Cooke RF, Jorge AM (2015) Impacts of temperament on Nellore cattle: physiological responses, feedlot performance, and carcass characteristics. Journal of Animal Science 93:5419-5429.

Grandin T (1983) Handling and processing feedlot cattle. In: Thompson GB, O'Mary CC (eds). The feedlot. Lea and Febiger, p 213-235.

Herborn KA, Graves JL, Jerem P, Evans NP, Nager R, Mccafferty DJ, Mckeegan DEF (2015) Skin temperature reveals the intensity of acute stress. Physiology \& Behavior 152:225-230.

Maffei WE (2009) Confinement reactivity. Revista Brasileira de Zootecnia 38:81-92.

Martello LS, Da Luz e Silva S, Costa Gomes R da, Silva Corte RRP da, Leme PR (2016) Infrared thermography as a tool to evaluate body surface temperature and its relationship with feed efficiency in Bos indicus cattle in tropical conditions. International Journal of Biometeorology 60(1):173-181.

Meola C, Carlomagno GM (2004) Recent advances in the use of infrared thermography. Measurement science and technology 15(9):R27.

Paranhos da Costa MJR, Costa e Silva EV, Chiquitelli Neto M (2002) Contribuição dos estudos de comportamento de bovinos para implementação de programas de qualidade de carne. In: Encontro Anual de Etologia. Natal, Sociedade Brasileira de Etologia, Anais... p 71-89.

Piovezan U, Cyrillo JN dos SG, Costa MJRP da (2013) Breed and selection line differences in the temperament of beef cattle. Acta Scientiarum. Animal Sciences 35(2):207-212.

Santos AS, Mcmanus C, Souza GS, Soriano BMA, Silva RAMS, Comastri Filho JÁ, Abreu UGP, Garcia JB (2005) Variações da temperatura corporal e da pele de vacas e bezerros das raças pantaneira e nelore no pantanal. Archivos de zootecnia 54(206-207):237-244.

Sartori DL, Cravo JCM, Barrero NG, Fiorelli J, Savastano Junior H, Nakanishi EY (2015) Modular panel with wood and particleboards of sugarcane bagasse for cattle handling facilities. Acta Scientiarum. Technology 37(1):3.

Sebastian T, Watts J, Stookey J, Buchanan F, Waldner C (2011) Temperament in beef cattle: Methods of measurement and their relationship to production. Canadian Journal of Animal Science 91(4):557-565.

Schaefer AL, Cook N, Tessaro SV, Deregt D, Desroches G, Dubeski PL, Tong AKW, Godson DL (2004) Early detection and prediction of infection using infrared thermography. Canadian Journal of Animal Science 84(1):73-80. 
Simon GE, Hoar BR, Tucker CB (2016) Assessing cowcalf welfare. Part 2: Risk factors for beef cow health and behavior and stockperson handling1. Journal of Animal Science 94:3488-3500.

Stewart M, Webster JR, Verkerk GA, Schaefer AL, Colyn JJ, Stafford KJ (2007) Non-invasive measurement of stress in dairy cows using infrared thermography. Physiology \& Behavior 92(3): 520-525.
Vetters MDD, Engle TE, Ahola JK, Grandin T (2013) Comparison of flight speed and exit score as measurements of temperament in beef cattle. Journal of Animal Science 91(1):374-381.

Xiong Z, Sun D-W, Pu H, Gao W, Dai Q (2017) Applications of emerging imaging techniques for meat quality and safety detection and evaluation: A review. Critical Reviews in Food Science and Nutrition 57(4):755-768. 